\title{
LEPROMATOUS LEPROSY PRESENTING AS GENITAL ULCER
}

\author{
S. Arunkumar ${ }^{1}$, B. Sowdhamani², S. Murugan ${ }^{3}$
}

\section{HOW TO CITE THIS ARTICLE:}

S. Arunkumar, B. Sowdhamani, S. Murugan. "Lepromatous Leprosy Presenting as Genital Ulcer". Journal of Evolution of Medical and Dental Sciences 2015; Vol. 4, Issue 45, June 04; Page: 7865-7868,

DOI: $10.14260 /$ jemds/2015/1146

ABSTRACT: Mycobacterium leprae can invade almost any part of the skin but most commonly affects the cooler parts rather than the warmer areas. Involvement of the male external genitalia although not very common due to the relatively higher temperature caused by the occlusive undergarments, can still be affected in leprosy. Most of the genital lesions seen on the leprosy patients are either nodules, patches, plaques, papules and or swelling of external genitalia. Herewith we are presenting a lepromatous leprosy patient presenting as genital ulcers in this era of syndromic management of Sexually Transmitted Infections (STI).

KEYWORDS: Lepromatous leprosy, Genital ulcer, Immune zones, Genital examination, STI.

INTRODUCTION: Leprosy is a chronic infectious disease caused by Mycobacterium leprae. Mycobacterium leprae has distinct predilection for cooler body areas.(1) Leprosy is usually seen over regions like face, elbows, trunk, knees, gluteal region and dorsal aspect of extremities.(2) Though certain regions like genitals, groins, axillae, scalp, palms and soles are said to be immune zones in leprosy, involvement of these regions have also been documented.(3) Herein, we report a case of lepromatous leprosy presenting as genital ulcers.

CASE REPORT: A 55 years old married male patient presented with complaints of genital ulcers for 2 years and with generalised itching all over the body for a period of 1 year. He also complained of raised skin lesions over the forehead since 1 year and over the abdomen for 5 months. History of hypopigmented skin patches over the abdomen was present. He had exacerbation of genital ulcers after sexual intercourse. He also complained of lower abdominal pain and burning micturition. Nasal stuffiness, epistaxis, numbness over extremities, arthralgia, redness and watering of eyes, swelling of legs, indigestion and dyspnoea were also present.

Patient was a smoker and alcoholic. He was married for15 years and had last marital sexual contact 2 weeks ago. He gave history of unprotected pre- marital sexual contact 17 years ago with an unknown lady. There was no history of previous venereal disease. Spouse assessment was done but there was no significant findings.

General examination of the patient showed mild pallor and pedal edema. Genital examination showed two, well defined, non-tender, indurated ulcers of size $0.5 \mathrm{~cm}$ with clean base over the prepuce (Fig. 1). Multiple, shiny, skin coloured papules and nodules of various size were seen infiltrating the preputial skin and the scrotum. Bilateral, multiple well defined, non-tender, discrete lymph nodes of various size was present over both inguinal regions.

Dermatological examination revealed multiple papules and nodules about $2 \times 1 \mathrm{cms}$ in size with shiny infiltrated appearance over both eyebrows. Bilateral infiltration of ears and face with madarosis was present (Fig. 2). Multiple well defined and few ill-defined hypopigmented macules was present over chest and neck. Multiple infiltrated papules and nodules about $0.5 \mathrm{cms}$ in size were present over abdomen (Fig. 3). 
Bilateral, symmetrical uniformly enlarged nontender peripheral nerves were present. Glove and stocking anaesthesia was present. Impaired sensation over the patches was present.

Laboratory investigations showed haemoglobin of $8.8 \mathrm{Gms}$. Peripheral smear showed normocytic, normochromic area. LFT, RFT, urine examination was normal. HIV and RPR were found to be non-reactive. Smear from preputial ulcer for acid fast bacilli (M. leprae) was found to be positive (Fig. 4). Smear for grams stain taken from the ulcers were negative. Slit skin smear taken from ear lobe for acid fast bacilli (M. leprae) was positive. There was severe stigma on genital ulcer and leprosy in our patient. Our patient has come to us mainly for the genital ulcer rather than for the skin lesions and was reluctant in giving consent for biopsy. As the smear from genital ulcer and ear lobe were conclusive for leprosy, and as a case holding technique in STI, we debarred biopsy from the genital lesion.

A diagnosis of lepromatous leprosy with genital ulcers was done based on history, clinical examination and demonstration of AFB in the slit skin smear. Patient was started on multi-bacillary multidrug regimen (MB-MDT).

Patient improved well with the above treatment. During the follow up period after 25 days, it was observed that the genital ulcers healed completely and the lepromatous infiltration over the trunk and genitals decreased significantly (Fig. 5-lesions after 15 days) and completed the MB-MDT regimen.

DISCUSSION: In leprosy, lesions are not commonly seen over the genitalia because of the relatively higher local temperature in this area due to the effect of heavy undergarments. The testicles and the scrotum have lower temperature that can favour the multiplication and growth of mycobacterium leprae.(4) Inspite of the above fact, the male genitalia was considered to be an immune zone for leprosy in various previous studies.(5)

Involvement of genitalia in leprosy patients also has not been much reported in literature, although leprosy is more prevalent in India. Only very few cases have been documented. It was found that $6.6 \%$,6) of leprosy patients had genital lesions according to the study done by Kumar et al. Arora et al reported that $2.9 \%$ of leprosy patients had genital lesions. (7) Most of the lesions were seen over the scrotum, prepuce and glans penis. Lesions over the penile shaft are usually rare. Most of the clinical lesions seen on the male external genitalia are nodules, patches, plaques, papules and swelling of external genitalia. Though genital lesions are seen in all spectrum in leprosy, they are most commonly seen in lepromatous, ${ }^{(8)}$ (LL), borderline lepromatous (BL) and borderline tuberculoid (BT) types.

Various studies have shown that leprosy granulomas and AFB are seen in scrotal skin of leprosy patients, ${ }^{(9)}$ even if there are no lesions seen clinically over it. It has been found that the acid fast bacilli (Mycobacterium Leprae) persists for a longer time in the dartos muscle even after adequate treatment,(10) in patients with leprosy.

The probable reasons for genital ulcers in our patient may be due to repeated trauma (Coital friction) over the infiltrated and weakened preputial skin.

Although rare, cutaneous lesions of leprosy can occur over the male genitalia. Most of the cases are missed either due to the lack of genital examination in leprosy patients by the examining doctor or health worker and also due to the reluctance by the patient to show their genitalia for examination. 
Clinical examination of genitalia is thus mandatory in all male leprosy patients. Suspected lesions on external genitalia should be sent for histopathological examination as early diagnosis and treatment can prevent complications due to leprosy.(11)

\section{REFERENCES:}

1. Anish SA. The relationship between surface temperature and dermal invasion in lepromatous leprosy. Int J lepr other Mycobact. Dis 1971; 39(4): 848-51.

2. Indira. D, Kaur. I, Sharma V. K, Das A. Palmo plantar lesions in leprosy. Indian J Lepr 1999; 71(2):167-72.

3. T. S. Rajashekar, Gurcharan singh and L. Chandra Naik. Immune Zones in leprosy. Indian Journal of Dermatlogy.2009 Jul-Sep; 54(3); 206-210.

4. Ebenso BE. Genital nodules and testicular hydrocoele in a case of relapsed lepromatous leprosy. Lep Rev 2000; 71: 81-2(PUBMED).

5. Fox H, Knott J. Leprous nodules of male genitalia. Int J. lepr.1924; 2: 445-6.

6. Kumar B, Kaur I, Rai R, Mandal S. K, Sharma V. K. Involvement of male genitalia in leprosy. Lepr. Rev. 2001; 72:70-77.

7. Arora S. K, Mukhija R. D, Mohan L, Girdhar M. A study of cutaneous lesions of leprosy on male external genitalia. Indian J. Lepr 1989; 61 (2): 222-4.

8. Sachin A. Badge, Alka V. Gosari, Nayan A Ramteerthkar, kalpana R. Sulhyan. Lepromatous Leprosy of prepuce-A case report. JKIMSU, Vol. 2, no 1, Jan-June 2013.

9. Ramanujam K, Ramu G. Wade's histoid lepromatous leprosy. Report of a clinical study .Lepr India.1969; 41:293-7.

10. Pandya N.J and Anita N.H. The value of scrotal biopsy in leprosy. Lepr. Rev 45(1974) 145-152.

11. Ramu G, Desikan KV. A study of scrotal biopsy in subsided cases of lepromatous leprosy. Lepr India.1979; 51:341-7(PUBMED).



Fig. 1

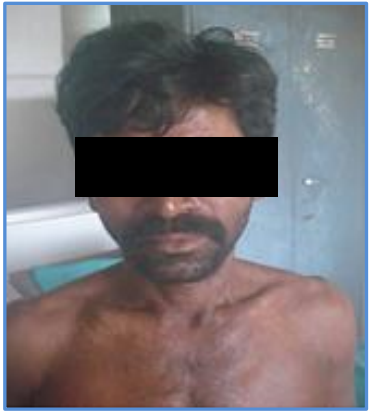

Fig. 2

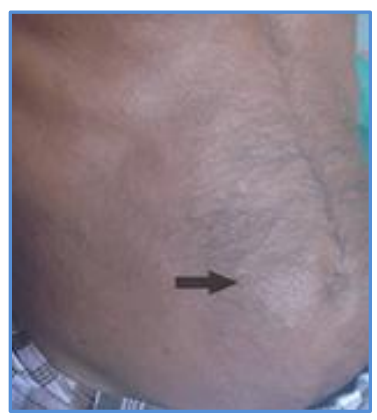

Fig. 3 


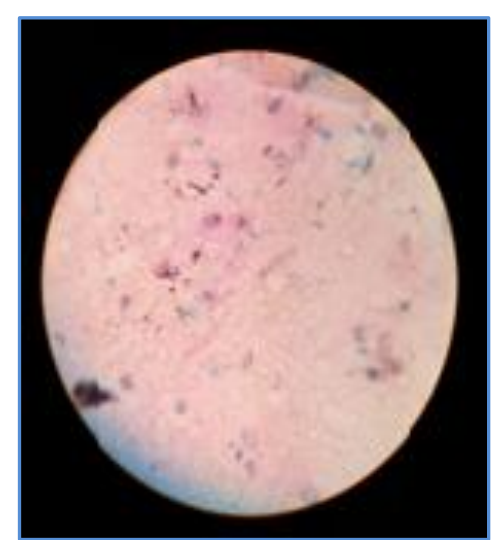

Fig. 4

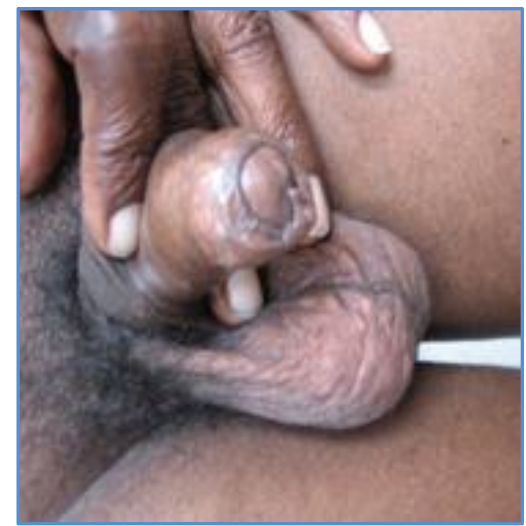

Fig. 5 (GenitalLesions after
15 days of MB-MDT)

\section{AUTHORS:}

1. S. Arunkumar

2. B. Sowdhamani

3. S. Murugan

\section{PARTICULARS OF CONTRIBUTORS:}

1. Professor and HOD, Department of STD, Government Royapettah Hospital, Kilpauk Medical College, Chennai.

2. Assistant Professor, Department of Dermatology and Venereology, Chettinad Medical College (Care), Rajiv Gandhi Salai, Kelambakkam, Kanchipuram.

FINANCIAL OR OTHER COMPETING INTERESTS: None
3. Assistant Professor, Department of STD, Chengalpattu Medical College, Chengalpattu.

\section{NAME ADDRESS EMAIL ID OF THE CORRESPONDING AUTHOR:}

Dr. S. Arunkumar,

Professor and HOD, Department of STD,

Government Royapettah Hospital,

Kilpauk Medical College,

Chennai-600014.

E-mail: arunssshc@gmail.com

Date of Submission: $14 / 05 / 2015$.

Date of Peer Review: 15/05/2015.

Date of Acceptance: 27/05/2015.

Date of Publishing: 04/06/2015. 